\title{
Modeling Bicycle Conflict on Non-Motorized Paths on Suburban College Campuses
}

\author{
Zachary Nerwinski, Ardeshir Faghri, Mingxin Li \\ Department of Civil \& Environmental Engineering, University of Delaware, Newark, DE, USA \\ Email: znerwin@udel.edu,faghri@udel.edu,lmx@udel.edu
}

How to cite this paper: Nerwinski, Z., Faghri, A. and Li, M.X. (2018) Modeling Bicycle Conflict on Non-Motorized Paths on Suburban College Campuses. Journal of Transportation Technologies, 8, 357-375. https://doi.org/10.4236/jtts.2018.84020

Received: September 6, 2018

Accepted: October 27, 2018

Published: October 30, 2018

Copyright ( 92018 by authors and Scientific Research Publishing Inc. This work is licensed under the Creative Commons Attribution International License (CC BY 4.0).

http://creativecommons.org/licenses/by/4.0/

(c) (i) Open Access

\begin{abstract}
Bicycling is an important way for college students and employees to get around campuses. With a rise in bicycling on campuses there comes a rise in bicycle collisions with pedestrians walking to and from classes and work. The literature review showed many papers involving bicycle conflict modeling but on roads with motor vehicles. While some aspects of this research can be applied to non-motorized paths, there is a lack of research strictly focusing on only bicycles and pedestrians. This study aims to fill this knowledge gap by developing a model to identify locations on roads and paths (hotspots) on college campuses that are likely to have a bicycle collision and predict the likelihood of a serious bicycle crash on a non-motorized path based on the characteristics of the path. This study identifies those interactions between bicyclists and pedestrians on non-motorized paths on a suburban college campus in Newark, USA. Findings suggest that pedestrian density of a path is a major factor in the maximum speed bicyclists can achieve. The wider the path is, the higher the maximum speed is that a bicyclist can obtain. This is because a wider path width decreases the pedestrian density. The grade of the path has little effect on bicycle speeds. The results of the models were displayed on a GIS map that is visually appealing to a viewer. The paths were color coded based on their level of safety, so it is easy to observe problematic areas of the network. This technique can be applied to the entire campus network of non-motorized paths to study the whole system. This can then be used by planners and designers to identify areas that need upgrading and improve the overall safety of the non-motorized path system.
\end{abstract}

\section{Keywords}

Conflict, Safety, Non-Motorized Path, Cyclist Violations, Suburban College Campus

\section{Introduction}

With the increase in population across the United States, there has been an in- 
creased demand on the transportation network [1]-[7]. The additional vehicles on the roads have created heavy congestion and delays for drivers [4] [8] [9] [10] [11] [12]. This congestion has brought a rise in alternative modes of transportation [13]-[18]. Bicycling is becoming an increasingly popular mode of transportation in the United States [19] [20] [21] [22] [23]. Users of bicycles can be divided into three categories: recreational, sport/exercise, and commuters. The category that this study focuses on is commuters, where people on college campuses are commuting to class or work. Bicycling is becoming more and more used as a way of commuting in a person's average day. From 2000 to 2008-2012, bicycling had the largest percentage increase for any commuter mode of transportation increasing from about 488,000 commuting workers to 786,000 [24]. This growth of bicycling affects college campuses as well, but it also varies by the type and size of the community. Cities have the highest rate of commuters bicycling to work at $1.0 \%$, followed by suburban at $0.4 \%$, and those outside metropolitan areas also at $0.4 \%$ [24]. College campuses exist in all three of these communities, therefore affected by the growth of bicycling.

Bicycling is a popular way for college students and faculty to get around on their campus [25] [26] [27]. A 2012 study of the campus showed that $22 \%$ of students bicycle to campus in good weather [28]. This is a very large percentage of their student population that is bicycling around campus. While this does mean more potential for bicycle collisions, colleges try to promote bicycling and walking on their campuses. Colleges want to encourage bicycling for many reasons including environmental conservation, simplicity for students, and to save the college money on vehicle parking. Saving money on vehicle parking is a huge financial incentive for colleges. In the same article [28], the author states that the Stanford University estimates it has saved $\$ 100$ million on construction and maintenance of parking facilities by promoting ways to reduce solo car commuting. Bicycling is notably one of the ways to reduce solo car commuting.

Unfortunately, this has created a rise in bicycle collisions with vehicles, pedestrians, and other bicycles [29]-[37]. This is especially critical on college campuses where the proportion of people biking and walking is higher than the average town. Conflicts can occur on both roads with vehicles, pedestrians and bicycles, and on paths that only have non-motorized transportation [38] [39]. Both instances can be very serious, as seen at the University of Delaware, where a pedestrian was hit and killed by a bicyclist on a non-motorized path [40].

There has been extensive research studying bicycle and pedestrian crashes. However, most of this research involves crashes with vehicles which are more common; one study by the University of California Transportation Center compiled crash data from three university campus areas; University of California-Berkley, University of California-Los Angeles, and California State University-Sacramento. The study combined crash data from the California Highway Patrol, the three campus' police units, and an online survey administered to each campus [41]. The study does include bicycle and pedestrian crashes occurred on multi-use paths and separated bike paths, but does not single these 
crashes out. The focus of the report involves crashes with vehicles, yet its methods could be applied to pedestrian and bicycle conflicts on non-motorized paths pavement [42] [43].

A report from Japan studied shared pavements that were used by bicyclists and pedestrians. These pavements were on the sides of roads, free of motor vehicles. The study compiled bicycle speed and pedestrian density data for the shared pavement. It found that as the number of pedestrians increased, the speeds of the bicycles decreased [44]. The study only collected this data on one shared pavement area in Kyusyu, Fukuoka. For this study, we will study paths of different widths and geometric characteristics to determine how pedestrians and bicyclists behave.

The literature review showed many papers involve bicycle conflict modeling but on roads with motor vehicles. While some aspects of this research can be applied to non-motorized paths, there is a lack of research strictly focusing on only bicycles and pedestrians. This study aims to fill this knowledge gap by developing a model to identify locations on roads and paths (hotspots) on college campuses that are likely to have a bicycle collision. The objectives of this research are trifold: 1) collect data on selected non-motorized paths on a suburban college campus; 2) design a model based on geometric variables of the non-motorized path as well as non-physical variables such as speed and density of users; and 3) create an output value and scale that will determine the safety of locations on non-motorized paths.

The final results of the model will give an output value for each location. A rating scale will be developed for the output value that will show how likely or unlikely it is for there to be a bicycle collision at that location. This will show the user of the model what locations are possible hotspots for collisions. The model results that can be used by planners and engineers will help make college campuses safer. It will show what attributes of a road or non-motorized path contribute most to bicycle collisions. Knowing what attributes contribute most to collisions will assist planners and engineers in avoiding those attributes as best as possible. They can design while keeping bicycle and pedestrian safety at the forefront of consideration. This study also offers areas to expand on the model. The focus for this study will be on suburban college campuses, but it could be expanded to include towns and communities. The study will also focus on non-motorized paths, but the model can be expanded to include path intersections as well.

The remainder of the paper is organized as follows. Section 2 introduces the methodology of the data collection and analysis. The data collection process is an innovative process that was used to collect the data for this project. This section also discusses how the raw data was processed and analyzed. Section 3 shows the final data collected and the various graphs that are developed from the data and discusses the several developed linear and non-linear models. The models are applied in GIS to create visual representations of the rating scale developed. From the analysis, recommendations are given of how to enhance the 
safety of non-motorized paths from the results of the modeling in Section 4.

\section{Methodology}

The University of Delaware campus was used to study and develop the model to identify bicycle conflict hotspots. The first step in the process was the design of the process and data variables, i.e., determining what variables were to be collected for analysis [45] [46] [47]. This was done by determining key geometric features as well as user characteristics. Once the variables were identified, the locations for data collection and analysis were selected. These were selected to include paths that are near both academic areas and residential areas on campus. Once the locations were identified, the data was collected. Geometric data was collected first, and then the user data was collected both in the summer and again in the fall when school was in full session. The different variables from the data collected were plotted on various graphs. Best fit lines were graphed to model the data. These equations were used as models to predict conflicts on the non-motorized paths.

\subsection{Variables}

The variables used in the model are categorized as either geometric variables or characteristic variables. The geometric variables are physical features of the paths. The characteristic variables describe the users of the paths and their actions.

\subsubsection{Geometric Variables}

- Width: The width of the path, measured in feet.

- Grade: The grade is measured along the direction of the path as a percent. It was taken at three points on each segment, the beginning, middle, and end.

- Cross Slope: The cross slope was measured at the same three points on each segment as the grade. It measures the slope perpendicular to the direction of the path.

- Horizontal Curvature: The horizontal curvature is categorized as either "curved" or "angled". The degree of curvature was not measured because some paths were not uniform or had multiple curves in the study segment. "Angled" means the paths bends at an angle, not as a curve.

\subsubsection{Characteristic Variables}

- Pedestrian Volume: The number of people walking or running on the path, divided into both directions. The volume is given as volume per fifteen-minute segment. Skateboarders were not counted in this data collection because they do not have the characteristics of pedestrians or bicycles. They were chosen to be omitted for this reason and because they are a rare occurrence.

- Bicycle Volume: The number of people riding bicycles on the path, divided into both directions. A person walking a bicycle is counted as a pedestrian, 
not a bicycle. The volume is given as volume per fifteen-minute segment.

- Crossing Pedestrian: The number of pedestrians who crossed the path perpendicular to the normal flow of users. The crossing pedestrian is given as number per fifteen-minute segment.

- Crossing Bicycle: The number of bicycles who crossed the path perpendicular to the normal flow of users. The crossing bicycle is given as number per fifteen-minute segment.

- Conflict: An observable situation in which a bicyclist nearly collides with a pedestrian or another bicyclist at any point on the study segment if their movements remain unchanged. A bicyclist weaving through pedestrians or adjusting speed safely is not a conflict. If a collision occurred, this was tallied as a conflict but also a description of the collision was recorded.

- Pedestrian Speed: The speed in feet per second of the pedestrians, divided into the two normal directions of the path.

- Bicycle Speed: The speed in feet per second of the bicyclists, divided into the two normal directions of the path.

\subsection{Locations}

The locations for the data collection were chosen to encompass different geometric features on the University of Delaware campus. The horizontal curvatures, widths, and grades vary at the different locations. The paths chosen are critical paths on the campus that are between residential buildings and academic buildings or between two academic buildings. Many students and faculty walking to and from classes throughout the day use these paths.

A total of twelve locations were chosen around campus. This number is a large enough sample to include different geometric features and user characteristics. For each path, a segment was chosen to collect the data. The segment chosen had uniform width and did not contain a major intersection with another path. However, there are building entrances, side door entrances, benches, and bike racks within the segments chosen. The segment lengths range from 45 feet to 176 feet long. The twelve locations for the data collection are shown on the map below (Figure 1) and the locations are listed in Table 1.

\subsection{Data Collection}

The data collection was done in two seasons, the summer and the fall. The summer data was collected first to have samples with smaller volumes when there are fewer people on campus. Data was collected again in the fall at all locations when all students and faculty were back on campus. This collection showed higher volumes as expected. The summer was also used to tweak the new data collection process to ensure it would be affective in the fall. The data was collected for two-hour periods at each location during midday on weekdays. The summer collections were done from 11:30 AM - 1:30 PM and were done once at eight of the twelve locations. The remaining four locations had little to no 


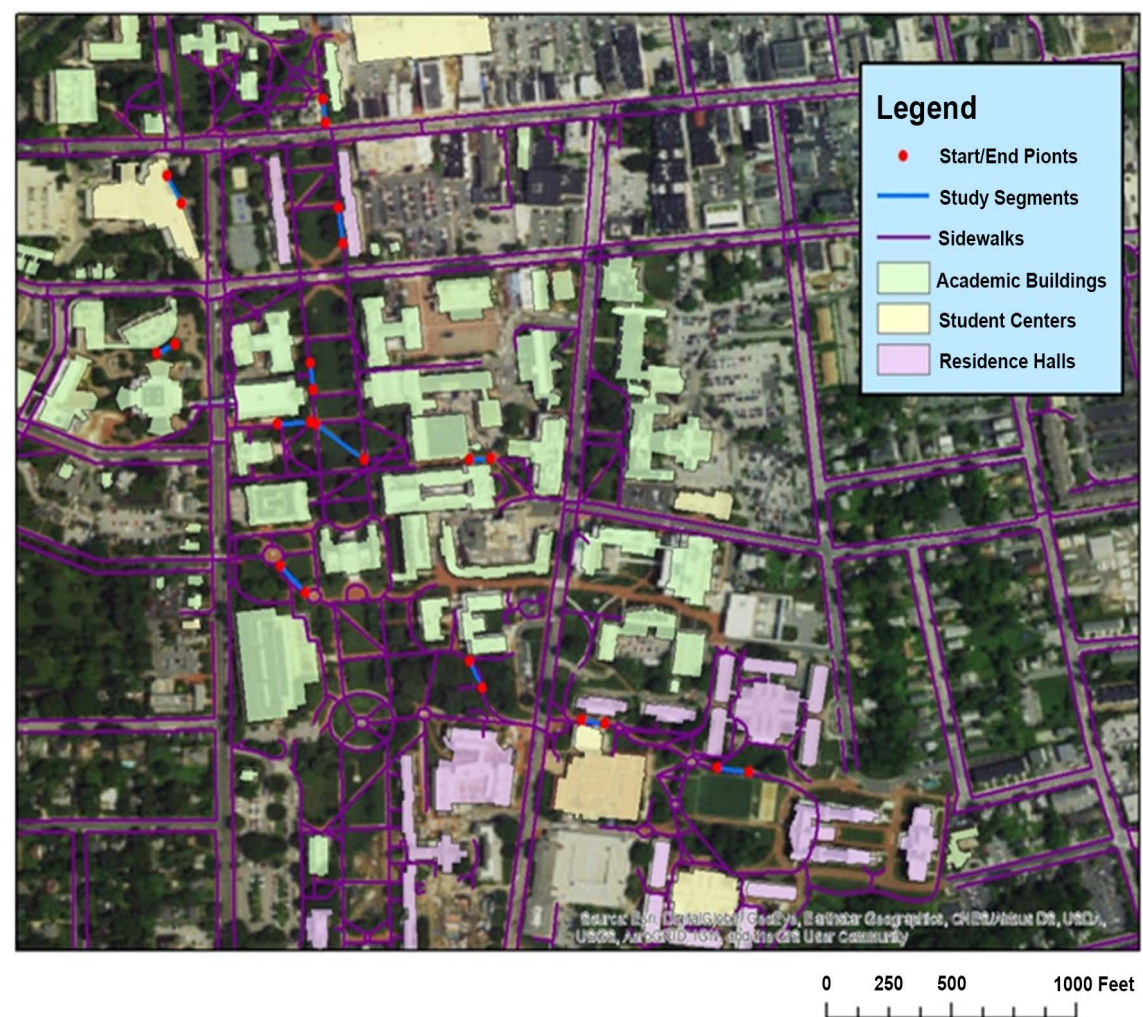

Figure 1. Data collection locations map.

Table 1. Data collection locations.

\begin{tabular}{ccc}
\hline Location Name & Width (ft.) & Length (ft.) \\
\hline Harrington Turf Path & 12 & 96 \\
Elliot Hall Path & 7.5 & 81 \\
Trabant Path & 18.5 & 95 \\
North Green, Sharp Hall Path & 15 & 118 \\
Kirkbride Path & 11 & 55 \\
North Green, Gore Hall Path & 15 & 72 \\
Mitchell Hall Path & 12 & 92 \\
North Green, Crossing Path & 10 & 176 \\
Evans Hall Path & 10 & 45 \\
Mentor's Circle Path & 15 & 127 \\
Allison Hall Path & 11 & 90.5 \\
Perkins Path & 16 & 73 \\
\hline
\end{tabular}

volume during the summer because they were located near residence halls that were unoccupied. In the fall, two data collections were done at each location.

The procedure of the data collection was developed specifically for this project. It consisted of $2-3$ persons sitting at the location next to the path to 
ensure they had an unobstructed view of the entire segment. One or two people collected the volume data, depending on the usage volume of the path. The collectors used counting sheets that were divided into 15-minute intervals over the two-hour collection. These collectors counted the number of pedestrians and bicycles in each direction, and recorded them in the appropriate 15-minute interval. These collectors also counted any crossing pedestrians or bicycles, also recording them in the appropriate 15-minute interval. Finally, these collectors counted any conflicts they saw and noted any collisions. The final person was the speed data collector. This person used several stopwatches to record the time it took randomly selected pedestrians and bicyclists to travel through the segment.

\subsection{Data Processing}

The data from the data collection sheets was input into Excel in separate files for the volume data and speed data. The volume data was input just as the collectors recorded on the collection sheets. As stated before, the speed data was input as times (in seconds) and the spreadsheet converted these times to speeds in feet per second. In the same Excel file, the low, mean, and high speeds were calculated for each fifteen-minute period in each direction. These speed values were copied into a final Excel sheet where they were matched with the corresponding volume values. The geometric data for the paths were added as well as time and location of the collection data. So, each line in this final spreadsheet is one fifteen-minute period of data collection, and contains the identification information, geometric characteristic, volume value, and calculated speed values.

From this data, separate spreadsheets were made to create the appropriate graphs needed for data analysis. This was done repeatedly for various graphs and the same process was used in Excel for modeling linear and non-linear equations to the data. After the models were developed, a scale was developed to rate the non-motorized paths. Using Geographic Information Systems software, the rating scale was used to create a visual representation of the ratings of the non-motorized paths on the University of Delaware campus.

\section{Data Analysis}

\subsection{Data}

The data from the volume and speed collections was entered into Excel format. The speeds were calculated from the times collected in the field. The low speed, mean speed, and max speed for pedestrians and bicycles in both directions were calculated. A sample of the data is shown in Table 2 that includes location and time identification, geometric features, volumes, and calculated speeds.

Each line represents a 15-minute data collection period. For formatting purposes for this sample, the Direction $\# 2$ data lines were moved under Direction \#1. The data for each location includes the location name and number, the width, 
Table 2. Data Sample-Fall.

\begin{tabular}{|c|c|c|c|c|}
\hline Location Name & Evans Hall Path & Mitchell Hall & $\begin{array}{c}\text { Mentors Circle } \\
\text { Path }\end{array}$ & $\begin{array}{c}\text { Harrington } \\
\text { Turf Path }\end{array}$ \\
\hline Number & 9 & 7 & 10 & 1 \\
\hline Width (ft) & 10 & 12 & 15 & 12 \\
\hline Avg Grade (\%) & 0.43 EB To Clbrn & 1.50 EB To Grn & 0.70 SB To Lib & 1.27 EB To Red \\
\hline $\begin{array}{c}\text { Avg Cross Slope } \\
(\%)\end{array}$ & $0.77 \mathrm{SB}$ & $1.50 \mathrm{SB}$ & $0.43 \mathrm{~EB}$ & $0.7 \mathrm{SB}$ \\
\hline H Curve & - & - & Curve & - \\
\hline Segment ID & 65 & 73 & 81 & 89 \\
\hline Date & $10 / 24 / 2016$ & $10 / 25 / 2016$ & $10 / 28 / 2016$ & $10 / 31 / 2016$ \\
\hline Weather & Sunny & Sun/Cloud & Sunny & Sunny \\
\hline Time & 2:15:00 PM & 2:15:00 PM & 2:15:00 PM & 2:15:00 PM \\
\hline Direction \#1 & EB (To Clbrn) & EB (To Grn) & NB (To Ment) & EB (To Red) \\
\hline Ped Volume \#1 & 110 & 17 & 215 & 44 \\
\hline Low Speed \#1 & 4.29 & 3.93 & 4.87 & 2.88 \\
\hline Mean Speed \# 1 & 4.84 & 4.30 & 5.33 & 3.27 \\
\hline Max Speed \#1 & 5.77 & 4.95 & 6.05 & 3.60 \\
\hline Bike Volume \#1 & 7 & 1 & 12 & 11 \\
\hline Low Speed \#1 & 7.50 & 0.00 & 8.58 & 5.93 \\
\hline Mean Speed \# 1 & 12.38 & 0.00 & 11.53 & 11.20 \\
\hline Max Speed \#1 & 15.52 & 0.00 & 14.60 & 13.33 \\
\hline Direction \#2 & WB (To Grn) & WB (To S Coll) & SB (To Lib) & WB (To Perk) \\
\hline Ped Volume \#2 & 91 & 23 & 210 & 17 \\
\hline Low Speed \#2 & 4.21 & 4.04 & 4.31 & 2.94 \\
\hline Mean Speed \#2 & 4.80 & 4.79 & 4.83 & 3.37 \\
\hline Max Speed \#2 & 5.63 & 5.71 & 5.50 & 3.95 \\
\hline Bike Volume \#2 & 2 & 2 & 6 & 7 \\
\hline Low Speed \#2 & 10.00 & 12.60 & 10.67 & 7.56 \\
\hline Mean Speed \#2 & 10.00 & 12.69 & 15.11 & 11.38 \\
\hline Max Speed \#2 & 10.00 & 12.78 & 19.54 & 13.71 \\
\hline Crossing Ped & - & - & - & - \\
\hline Crossing Bike & - & - & - & - \\
\hline Conflict & - & - & - & - \\
\hline
\end{tabular}

the average grade, the average cross slope, any horizontal curvature, a given segment ID number, the weather, and the time and date. Following that information is the pedestrian and bicycle volumes for each direction as well as the minimum, mean, and maximum speeds for pedestrians and bicycles.

There are 16 hours of summer data collected, which breaks down into 64 fifteen-minute periods. For the fall data, there are 50 hours of data for 200 fif- 
teen-minute periods. As stated before, all twelve locations were counted twice in the fall. However, location 3 (Trabant Path), was counted a third time because of weather. That is why there is an additional two hours of data for the fall. Over the summer and fall, this totals 66 hours of data collected which breaks down into 264 fifteen-minute periods.

\subsection{Graphing the Data}

After the data was processed and put into an Excel format, the different variables were graphed against each other and the results are shown below. The independent variable in this section, shown on the $\mathrm{x}$-axis, is the volume of pedestrians on the path. The pedestrian volume is used rather than the bicycle volume because the pedestrian volume is much larger and governs the density of the path. The dependent variable that we want to focus on is the speed of the bicycles. This is because if bicycles are moving faster compared to the pedestrians, it is more likely that a collision will be serious and that a bicyclist is less able to move out of the way. Therefore, the models that will be developed will be generating bicycle speeds as an output.

Figure 2 is a sample graph from the fall data, and it is showing the pedestrian volume on the $\mathrm{x}$-axis and the mean speed of the bicycles of the corresponding segment on the y-axis. The pedestrian volume shown is the volume in the same direction as the corresponding bicycle speed shown on the y-axis. The data collection process yielded large amounts of data and many characteristics of the non-motorized paths. The many characteristics collected were graphed against each other to see how they affect each other. The data analysis revealed many trends in the data that will be modeled in the next section.

There were several important trends that were observed. When the pedestrian volume was first graphed against the bicycle speed, there did not appear to be a trend because paths of different widths experienced very different volumes. Once the volume was converted to the density term, volume per foot of width of the path, the data points were standardized and showed a downward trend in bicycle speed as the pedestrian density increased. This is a logical trend because when there are more pedestrians on a non-motorized path, a bicycle is not able to reach a high speed.

The second important trend that was observed was the relationship between path width and bicycle speed. When the path width was graphed as the independent variable and the bicycle speed as the dependent variable, the graph appeared to show an upward trend in the bicycle speed as the path width increased. This is also a logical trend because it would mean the wider paths have lower pedestrian densities than the narrower paths and bicycles are able to travel at a faster speed. This is an important trend because it would allow paths to be evaluated without having to collect pedestrian volume data. Both trends mentioned will be modeled with both linear and non-linear equations next to confirm the assumptions. These will be the basis for a rating scale to evaluate the non-motorized paths. 


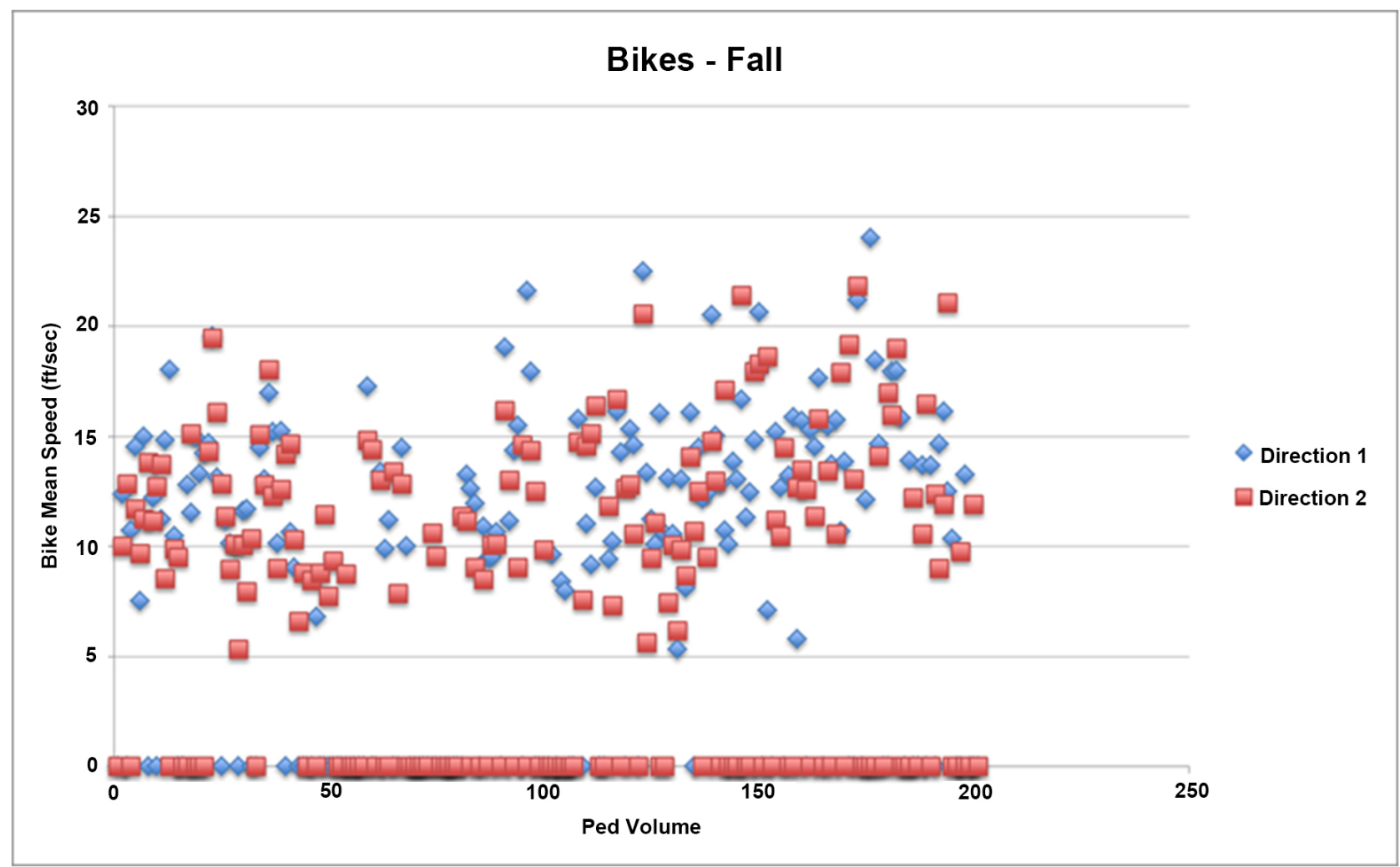

Figure 2. Ped volume vs bike mean speed-Fall.

\subsection{Modeling Results}

The second objective of this study is to develop a model using non-physical characteristics such as volume and density as well as geometric characteristics of the paths. In this section, the non-physical characteristics such as pedestrian volume and density will be used create a model to predict the maximum possible speed of a bicycle. To reiterate, the volume data was collected by students on selected paths in fifteen-minute periods. The density term that will be used, Pedestrian Volume per Ft of Width, was developed by dividing the volume of each fifteen-minute period by the width of the path. This was done to be able to compare paths of different widths to each other.

For the non-physical characteristics modeling, a best fit equation was developed but not using all of the data points. Instead, data points were selected that represented the highest speed a bicycle achieved at each pedestrian density. This was done because the goal is to model the maximum speed a bicycle could achieve at a given density, rather than what the average speed would be. Fitting the entire data set would not give an accurate model for the maximum achievable speed. Both the mean speed and maximum speed will be used to create the models.

Model 1

$$
\text { Maximum Bicycle Speed }=\left(-0.7652 * \frac{\text { Pedestrian Volume }}{\text { Path Width }}\right)+30.388
$$


Maximum Bicycle Speed is given in feet per second.

Pedestrian Volume is given as the volume in one direction in a fifteen-minute period.

Path Width is given in feet.

Model 2

$$
\text { Maximum Bicycle Speed }=\left(-0.4941 * \frac{\text { Total Pedestrian Volume }}{\text { Path Width }}\right)+31.11
$$

Model 3

$$
\text { Maximum Bicycle Speed }=(0.702 * \text { Path Width })+11.891
$$

The results of the three models are compared against each other. However, each model requires different inputs. All three models require path width as an input value. Models 1 and 2 require pedestrian volumes as inputs values as well. Model 1 uses the pedestrian volume in one direction of travel, while Model 2 uses the total pedestrian volume in both directions.

A table in Excel was set up to compare the three models to each other using pre-determined input values. The path widths start at $4 \mathrm{ft}$. and increase in $2 \mathrm{ft}$. increments up to $20 \mathrm{ft}$. At each of the path widths, the single direction pedestrian volumes start at 30 users per fifteen-minutes. The number of users increases by 30 and goes up to 300 users per fifteen-minutes. For the total volume, the single direction volume was doubled. So, the total volume starts at 60 users per fifteen-minutes and increases to 600 users per fifteen-minutes. These values are realistic because the path widths on the University of Delaware campus range from $7.5 \mathrm{ft}$. to $18.5 \mathrm{ft}$. The highest pedestrian volumes observed were 201 users per fifteen-minutes in one direction and 566 users per fifteen-minutes combined both directions.

There are a few observations that should be noted about the comparison tables. The first is that the resulting values in the Model 1, Model 2, and Model 3 columns are bicycle speeds given in feet per second. These speeds are the values that the model gives as the maximum possible bicycle speed for the inputs given. The second observation that should be noted is that some of these values are less than the maximum speeds observed in the data collection. This is because the model was fit to selected data points where some values are lower than the linear fit and some are higher than the linear fit. The final observation is that some values the model gives are negative. This occurs when the pedestrian volume is extremely high for the size of the path, and this only happens at the $4-\mathrm{ft}, 6-\mathrm{ft}$, and 8 - $\mathrm{ft}$ widths. The negative values occur because the models are linear and decrease as the pedestrian density of the path increases. The high volumes on narrow paths create pedestrian densities that may be at jam density or are unrealistic. For these reasons, the Models 1 and 2 result in some negative bicycle speeds at high densities.

The three models that have been developed all output maximum bicycle speeds for the given path with and pedestrian volumes. These models can be used to evaluate the safety of the non-motorized paths on the University of De- 
laware campus. To use these models to evaluate the paths, an output scale must be created. The numerical results of the models will fall into safety levels that show how safe or unsafe the non-motorized path is (Table 3).

\subsection{GIS Applications}

Geographic Information Systems are able to display the model results on a visually appealing map that is easy for viewers to understand. The maps created can be displayed for planners and designs who can work to improve the safety of non-motorized paths. The maps identify key areas that are more dangerous than others on campus.

Using only the path width, the study segments can be input into Model 3 to determine the levels of safety. The other two models can be used as well; however a pedestrian volume must be chosen and input into the model along with the path width. The results of Model 3 using the 12 study segments are shown in Table 4.

Five of the study segments fall into the Moderately Safe level of safety, while the remaining seven fall into the Moderately Unsafe level of safety. None of the paths studied are determined to be Safe or Unsafe. However, this is only using the outputs from Model 3. If pedestrian data is used, then Model 1 or Model 2 is also able to be used.

These results from Model 3 can then be displayed on a map using the ArcMap program. The color-coded study segments are created as a layer and are overlaid on top of satellite imagery of the campus. A sidewalks layer obtained from the State of Delaware First Map website is also overlaid onto the satellite imagery to show all of the paths on campus. The sidewalks layer includes both sidewalks next to roads and walking paths around campus that are defined as non-motorized paths. This map is show in the following figure.

The results of the models were displayed on a GIS map (Figure 3) that is visually appealing to a viewer. The paths were color coded based on their level of safety, so it is easy to observe problematic areas of the network. This technique can be applied to the entire campus network of non-motorized paths to study the whole system. This can then be used by planners and designers to identify areas that need upgrading and improve the overall safety of the non-motorized path system.

\section{Conclusions}

There are several conclusions that can be made from this non-motorized path analysis. These conclusions are based on the data collected and analyzed from the University of Delaware campus. Pedestrian density of a path is a major factor in the maximum speed bicyclists can achieve. The wider the path is, the higher the maximum speed is that a bicyclist can obtain. This is because a wider path width decreases the pedestrian density. The grade of the path has little effect on bicycle speeds. 
Table 3. Modeloutput values.

\begin{tabular}{|c|c|c|c|c|c|c|c|c|c|}
\hline \multicolumn{10}{|c|}{ Model 1 Output Values } \\
\hline Single & $4 \mathrm{ft}$ & $6 \mathrm{ft}$ & $8 \mathrm{ft}$ & $10 \mathrm{ft}$ & $12 \mathrm{ft}$ & $14 \mathrm{ft}$ & $16 \mathrm{ft}$ & $18 \mathrm{ft}$ & $20 \mathrm{ft}$ \\
\hline Direction & Path & Path & Path & Path & Path & Path & Path & Path & Path \\
\hline 30 Peds & 24.65 & 26.56 & 27.52 & 28.09 & 28.48 & 28.75 & 28.95 & 29.11 & 29.24 \\
\hline 60 Peds & 18.91 & 22.74 & 24.65 & 25.80 & 26.56 & 27.11 & 27.52 & 27.84 & 28.09 \\
\hline 90 Peds & 13.17 & 18.91 & 21.78 & 23.50 & 24.65 & 25.47 & 26.08 & 26.56 & 26.94 \\
\hline 120 Peds & 7.43 & 15.08 & 18.91 & 21.21 & 22.74 & 23.83 & 24.65 & 25.29 & 25.80 \\
\hline 150 Peds & 1.69 & 11.26 & 16.04 & 18.91 & 20.82 & 22.19 & 23.21 & 24.01 & 24.65 \\
\hline 180 Peds & -4.05 & 7.43 & 13.17 & 16.61 & 18.91 & 20.55 & 21.78 & 22.74 & 23.50 \\
\hline 210 Peds & -9.79 & 3.61 & 10.30 & 14.32 & 17.00 & 18.91 & 20.34 & 21.46 & 22.35 \\
\hline 240 Peds & -15.52 & -0.22 & 7.43 & 12.02 & 15.08 & 17.27 & 18.91 & 20.19 & 21.21 \\
\hline 270 Peds & -21.26 & -4.05 & 4.56 & 9.73 & 13.17 & 15.63 & 17.48 & 18.91 & 20.06 \\
\hline 300 Peds & -27.00 & -7.87 & 1.69 & 7.43 & 11.26 & 13.99 & 16.04 & 17.63 & 18.91 \\
\hline \multicolumn{10}{|c|}{ Model 2 Output Values } \\
\hline Both & $4 \mathrm{ft}$ & $6 \mathrm{ft}$ & $8 \mathrm{ft}$ & $10 \mathrm{ft}$ & $12 \mathrm{ft}$ & $14 \mathrm{ft}$ & $16 \mathrm{ft}$ & $18 \mathrm{ft}$ & $20 \mathrm{ft}$ \\
\hline Directions & Path & Path & Path & Path & Path & Path & Path & Path & Path \\
\hline 60 Peds & 23.70 & 26.17 & 27.40 & 28.15 & 28.64 & 28.99 & 29.26 & 29.46 & 29.63 \\
\hline 120 Peds & 16.29 & 21.23 & 23.70 & 25.18 & 26.17 & 26.87 & 27.40 & 27.82 & 28.15 \\
\hline 180 Peds & 8.88 & 16.29 & 19.99 & 22.22 & 23.70 & 24.76 & 25.55 & 26.17 & 26.66 \\
\hline 240 Peds & 1.46 & 11.35 & 16.29 & 19.25 & 21.23 & 22.64 & 23.70 & 24.52 & 25.18 \\
\hline 300 Peds & -5.95 & 6.41 & 12.58 & 16.29 & 18.76 & 20.52 & 21.85 & 22.88 & 23.70 \\
\hline 360 Peds & -13.36 & 1.46 & 8.88 & 13.32 & 16.29 & 18.40 & 19.99 & 21.23 & 22.22 \\
\hline 420 Peds & -20.77 & -3.48 & 5.17 & 10.36 & 13.82 & 16.29 & 18.14 & 19.58 & 20.73 \\
\hline 480 Peds & -28.18 & -8.42 & 1.46 & 7.39 & 11.35 & 14.17 & 16.29 & 17.93 & 19.25 \\
\hline 540 Peds & -35.59 & -13.36 & -2.24 & 4.43 & 8.88 & 12.05 & 14.43 & 16.29 & 17.77 \\
\hline 600 Peds & -43.01 & -18.30 & -5.95 & 1.46 & 6.41 & 9.93 & 12.58 & 14.64 & 16.29 \\
\hline \multicolumn{10}{|c|}{ Model 3 Output Values } \\
\hline & $4 \mathrm{ft}$ & $6 \mathrm{ft}$ & $8 \mathrm{ft}$ & $10 \mathrm{ft}$ & $12 \mathrm{ft}$ & $14 \mathrm{ft}$ & $16 \mathrm{ft}$ & $18 \mathrm{ft}$ & $20 \mathrm{ft}$ \\
\hline & Path & Path & Path & Path & Path & Path & Path & Path & Path \\
\hline $\begin{array}{c}\text { All Ped } \\
\text { Volumes }\end{array}$ & 14.70 & 16.10 & 17.51 & 18.91 & 20.32 & 21.72 & 23.12 & 24.53 & 25.93 \\
\hline \multicolumn{10}{|c|}{ Legend: Levels of Safety Color Code. } \\
\hline \multicolumn{10}{|l|}{ Safe } \\
\hline \multicolumn{10}{|c|}{ Moderately Safe } \\
\hline \multicolumn{10}{|c|}{ Moderately Unsafe } \\
\hline Unsafe & & & & & & & & & \\
\hline
\end{tabular}

An advantage of this analysis is that it can be used by other universities and planners to study non-motorized path networks. Other universities can apply this analysis in two ways. The first way would be to collect data on their own campus and run the models using the data collected. This process is more time consuming and requires extensive data collection. The minimum data needed 
Table 4. Model 3-study segment outputs.

\begin{tabular}{ccc}
\hline & Width (ft) & Model 3 Output (ft/s) \\
\hline Harrington Turf Path & 12 & 20.31 \\
Elliot Hall Path & 7.5 & 17.15 \\
Trabant Path & 18.5 & 24.87 \\
North Green, Sharp Hall Path & 15 & 22.42 \\
Kirkbride Path & 11 & 19.61 \\
North Green, Gore Hall Path & 15 & 22.42 \\
Mitchell Hall Path & 12 & 20.31 \\
North Green, Crossing Path & 10 & 18.91 \\
Evans Hall Path & 10 & 18.91 \\
Mentor's Circle Path & 15 & 22.42 \\
Allison Hall Path & 11 & 19.61 \\
Perkins Path & 16 & 23.12 \\
\hline
\end{tabular}

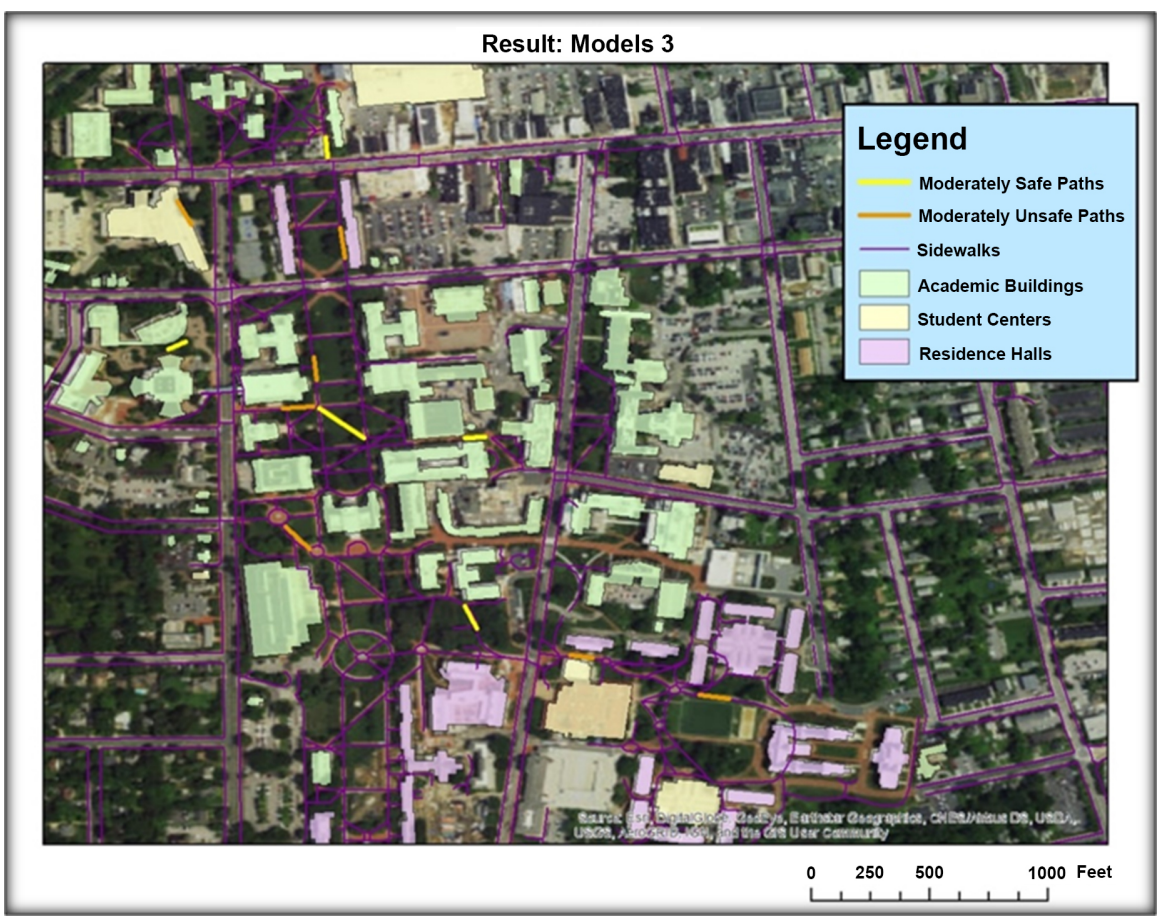

Figure 3. Model 3-study segment map.

would be path width data, but to do a full analysis using all three of the models, pedestrian volume data would need to be collected. This collection process can be very resource and time consuming. However, the method would be very useful for university planners to analyze the safety of the non-motorized path network.

The second way that other universities can apply this analysis is by simply applying the findings directly to their planning. This analysis has shown that path 
width and pedestrian density are the major factors in bicycle speeds. Wider paths offer more space for bicycles to build up speed and can make the path unsafe. Narrower paths with higher pedestrian densities can keep bicycles at lower speeds and increase the level of safety. Planners can use these findings and apply them directly to improving their non-motorized path network.

The data collection, analysis, and models developed are useful tools to study the non-motorized paths on the University of Delaware campus. These tools can also be applied to other suburban universities that have similar campus traits, as discussed in the previous section. However, with three models developed, it is difficult to say which is the "best" at evaluating the safety of non-motorized paths. All three of the models have their advantages and disadvantages. Model 3 is easier to use since it only uses path width as an input. However, Model 1 and Model 2 are more accurate because they use pedestrian volume data as well as path width. Model 2 uses pedestrian data for both directions on the path, which is an advantage over Model 1 because both directions give a more accurate pedestrian density. So, if pedestrian data is available, Model 2 is the most accurate and useful model.

After the paths are evaluated for their level of safety, planners and designers can work to improve the safety in key areas. The results of this analysis show that maximum bicycle speed is determined by a number of factors and is a key component in the overall safety of a non-motorized path. Therefore, planners and designers should focus on ways to reduce bicycle speeds on campus.

The bicycle speed control devices (e.g., "Slow Biking" signs, Speed bumps and speed humps, narrower paths) have the potential to reduce bicycle speeds and improve the safety of non-motorized paths. These devices can be studied in the field to see if they indeed reduce bicycle speeds, and if so, by how much. To be studied, they can be temporarily installed in a location on campus, and data can be collected using the same method that was used to collect the data for this study. The speeds of bicycles with the certain devices can be compared to the speeds in the same location at the same time of day. The studies would need to be done on the same day of the week to minimize other variables. If any of the devices prove successful, they can be implemented around campus permanently. The devices implemented could help improve the overall safety of the non-motorized path network.

\section{Acknowledgements}

This work was partially supported by the Delaware Center for Transportation (DCT) co-sponsored by the University of Delaware and the Delaware Department of Transportation. The authors express their sincere gratitude to DCT for providing their extensive data sources. The authors would also like to thank the numerous undergraduate students who assisted with the data collection for this work. Undergraduates Michaella Becker, Jessica Browne, Audrey Eldridge, David Furbish, Andrew Major, Kyle Verdi, and Andrew Yurish were invaluable to this research. 


\section{Conflicts of Interest}

The authors declare no conflicts of interest regarding the publication of this paper.

\section{References}

[1] Zhang, L., Xu, W. and Li, M. (2009) Co-Evolution of Transportation and Land Use: Modeling Historical Dependencies in Land Use and Transportation Decision-Making. No. OTREC-RR-09-08.

[2] Li, M. (2011) Modeling Network-Wide Impacts of Traffic Bottleneck Mitigation Strategies under Stochastic Capacity Conditions. The University of Utah, Salt Lake City.

[3] Jia, A., Zhou, X., Li, M., Rouphail, N. and Williams, B. (2011) Incorporating Stochastic Road Capacity into a Day-to-Day Traffic Simulation and Traveler Learning Framework: Model Development and Case Study. Transportation Research Record: Journal of the Transportation Research Board, 2254, 112-121. https://doi.org/10.3141/2254-12

[4] Li, M., Zhou, X. and Rouphail, N.M. (2017) Quantifying Travel Time Variability at a Single Bottleneck Based on Stochastic Capacity and Demand Distributions. Journal of Intelligent Transportation Systems. Technology, Planning, and Operations, 21, 79-93. https://doi.org/10.1080/15472450.2016.1163639

[5] Zhou, X., Rouphail, N. and Li, M. (2011) Analytical Models for Quantifying Travel Time Variability Based on Stochastic Capacity and Demand Distributions. Transportation Research Board 90th Annual Meeting, Washington DC, 23-27 January 2011, 19 p.

[6] Li, M., Zhou, X. and Rouphail, N. (2011) Planning-Level Methodology for Evaluating Traveler Information Provision Strategies under Stochastic Capacity Conditions. Transportation Research Board 90 th Annual Meeting, Washington DC, 23-27 January 2011, Article No. 11-3002.

[7] Taromi, R., DuRoss, M., Chen, B., Faghri, A., Li, M. and DeLiberty, T. (2015) A Multi-Objective Land Development Optimization Model: The Case of New Castle County, Delaware. Transportation Planning and Technology, 38, 277-304. https://doi.org/10.1080/03081060.2014.997450

[8] Li, M., Zhou, X. and Rouphail, N. (2011) Quantifying Benefits of Traffic Information Provision under Stochastic Demand and Capacity Conditions: A Multi-Day Traffic Equilibrium Approach. 2011 14th International IEEE Conference on Intelligent Transportation Systems (ITSC), Washington DC, 5-7 October 2011, 2118-2123.

[9] Hamad, K., Faghri, A. and Li, M. (2015) Forecasting Model for Vehicular Demand: an Alternative Methodology in the Context of Developing Countries. The Journal of Developing Areas, 49, 125-143. https://doi.org/10.1353/jda.2015.0006

[10] Laghaei, J., Faghri, A. and Li, M. (2016) Impacts of Home Shopping on Vehicle Operations and Greenhouse Gas Emissions: Multi-Year Regional Study. International Journal of Sustainable Development \& World Ecology, 23, 381-391. https://doi.org/10.1080/13504509.2015.1124471

[11] Li, M. and Faghri, A. (2016) Applying Problem-Oriented and Project-Based Learning in a Transportation Engineering Course. Journal of Professional Issues in Engineering Education and Practice, 142, Article ID: 04016002. https://doi.org/10.1061/(ASCE)EI.1943-5541.0000274 
[12] Li, M., Rouphail, N.M., Mahmoudi, M., Liu, J. and Zhou, X. (2017) Multi-Scenario Optimization Approach for Assessing the Impacts of Advanced Traffic Information under Realistic Stochastic Capacity Distributions. Transportation Research Part C: Emerging Technologies, 77, 113-133. https://doi.org/10.1016/j.trc.2017.01.019

[13] Scott, M., Li, M., Barnes, P., Stavru, W., Dayan, S., Jones, C., Matthews, J., Cragle, J. Edwards, S., Rahall, N. and Nguyen, T. (2016) The Use of Smart Growth Scorecards/Assessment Tools to Advance Sustainable Land Use Practices. Institute for Public Administration.

[14] Scott, M., Kelly, C., Collins, E., Lewis, J., Faghri, A. and Li, M. (2017) Research of Viable Attributes and Potential to Integrate Curbside Intercity Buses. Transportation Research Board 96th Annual Meeting, Washington DC, 8-12 January 2017, Article No. 17-06609.

[15] Vaughan, M.L., Faghri, A. and Li, M. (2017) An Interactive Expert System Based Decision Making Model for the Management of Transit System Alternate Fuel Vehicle Assets. Intelligent Information Management, 9, 1-20. https://doi.org/10.4236/iim.2017.91001

[16] Vaughan, M.L., Faghri, A. and Li, M. (2017) Knowledge-Based Decision-Making Model for the Management of Transit System Alternative Fuel Infrastructures. International Journal of Sustainable Development \& World Ecology, 1-11.

[17] Shahpar, A., Faghri, A. and Li, M. (2018) Emission and Life-Cycle Assessment of Alternative-Fuel Buses: A Case Study of the Delaware Authority of Regional Transit. International Journal of Sustainable Development \& World Ecology, 25, 290-302. https://doi.org/10.1080/13504509.2017.1390794

[18] Faghri, A., Li, M. and Russell, S. (2015) Application of Global Positioning System (GPS) to Travel Time and Delay Measurements. Delaware Center for Transportation, Newark.

[19] Turner, S., Hottenstein, A. and Shunk, G. (1997) Bicycle and Pedestrian Travel Demand Forecasting: Literature Review.

[20] Pucher, J. and Buehler, R. (2006) Why Canadians Cycle More than Americans: A Comparative Analysis of Bicycling Trends and Policies. Transport Policy, 13, 265-279. https://doi.org/10.1016/j.tranpol.2005.11.001

[21] Rutter, H., Cavill, N., Racioppi, F., Dinsdale, H., Oja, P. and Kahlmeier, S. (2013) Economic Impact of Reduced Mortality Due to Increased Cycling. American Journal of Preventive Medicine, 44, 89-92. https://doi.org/10.1016/j.amepre.2012.09.053

[22] Li, M. and Faghri, A. (2014) Cost-Benefit Analysis of Added Cycling Facilities. Transportation Research Record: Journal of the Transportation Research Board, No. 2468, 55-63.

[23] Li, M. and Faghri, A. (2018) A Framework to Analyze the Economic Feasibility of Cycling Facilities. In: Bicycle Urbanism, Routledge, London, 140-159.

[24] McKenzie, B. (2014) Modes Less Traveled-Bicycling and Walking to Work in the United States: 2008-2012. US Census Bureau, New York.

[25] Balsas, C.J. (2003) Sustainable Transportation Planning on College Campuses. Transport Policy, 10, 35-49. https://doi.org/10.1016/S0967-070X(02)00028-8

[26] Rodriguez-Seda, J.D., Benekohal, R.F. and Morocoima-Black, R. (2008) Pedestrian, Bicycle, and Vehicle Traffic Conflict Management in Big Ten University Campuses. Transportation Research Board 87th Annual Meeting, Washington DC, 13-17 January 2008, Article No. 08-2213.

[27] Akar, G., Fischer, N. and Namgung, M. (2013) Bicycling Choice and Gender Case 
Study: The Ohio State University. International Journal of Sustainable Transportation, 7, 347-365. https://doi.org/10.1080/15568318.2012.673694

[28] Schmitt, A. (2014) Five Ways Colleges Are Coaxing Students out of Their Cars.

[29] Stutts, J.C. and Hunter, W.W. (1999) Motor Vehicle and Roadway Factors in Pedestrian and Bicyclist Injuries: An Examination Based on Emergency Department Data. Accident Analysis \& Prevention, 31, 505-514. https://doi.org/10.1016/S0001-4575(99)00007-X

[30] Maki, T., Kajzer, J., Mizuno, K. and Sekine, K. (2003) Comparative Analysis of Vehicle-Bicyclist and Vehicle-Pedestrian Accidents in Japan. Accident Analysis \& Prevention, 35, 927-940. https://doi.org/10.1016/S0001-4575(02)00101-X

[31] Wang, Y. and Nihan, N.L. (2004) Estimating the Risk of Collisions between Bicycles and Motor Vehicles at Signalized Intersections. Accident Analysis \& Prevention, 36, 313-321. https://doi.org/10.1016/S0001-4575(03)00009-5

[32] Kim, J.K., Kim, S., Ulfarsson, G.F. and Porrello, L.A. (2007) Bicyclist Injury Severities in Bicycle-Motor Vehicle Accidents. Accident Analysis \& Prevention, 39, 238-251. https://doi.org/10.1016/j.aap.2006.07.002

[33] Wier, M., Weintraub, J., Humphreys, E.H., Seto, E. and Bhatia, R. (2009) An Area-Level Model of Vehicle-Pedestrian Injury Collisions with Implications for Land Use and Transportation Planning. Accident Analysis \& Prevention, 41, 137-145. https://doi.org/10.1016/j.aap.2008.10.001

[34] Chong, S., Poulos, R., Olivier, J., Watson, W.L. and Grzebieta, R. (2010) Relative Injury Severity among Vulnerable Non-Motorised Road Users: Comparative Analysis of Injury Arising from Bicycle-Motor Vehicle and Bicycle-Pedestrian Collisions. Accident Analysis \& Prevention, 42, 290-296. https://doi.org/10.1016/j.aap.2009.08.006

[35] Frey, R., Faghri, A. and Li, M. (2014) Development of an Expert System for Effective Countermeasure Identification at Rural Unsignalized Intersections. Transportation Research Board 93rd Annual Meeting, Washington DC, 12-16 January 2014, Article No. 14-3494.

[36] Lee, J., Abdel-Aty, M. and Jiang, X. (2015) Multivariate Crash Modeling for Motor Vehicle and Non-Motorized Modes at the Macroscopic Level. Accident Analysis \& Prevention, 78, 146-154. https://doi.org/10.1016/j.aap.2015.03.003

[37] Li, M., Faghri, A. and Fan, R. (2017) Determining Ideal Locations for Radar Speed Signs for Maximum Effectiveness: A Review of the Literature. Delaware Center for Transportation, Newark.

[38] Heesch, K.C., Sahlqvist, S. and Garrard, J. (2011) Cyclists' Experiences of Harassment from Motorists: Findings from a Survey of Cyclists in Queensland, Australia. Preventive Medicine, 53, 417-420. https://doi.org/10.1016/j.ypmed.2011.09.015

[39] Humphrey, S., Faghri, A. and Li, M. (2013) Health and Transportation: The Dangers and Prevalence of Road Rage within the Transportation System. American Journal of Civil Engineering and Architecture, 1, 156-163.

[40] Horn, B. (2016) Student Hit by Bike at UD Dies Months after Crash.

[41] Loukaitou-Sideris, A., Medury, A., Fink, C., Grembek, O., Shafizadeh, K., Wong, N. and Orrick, P. (2014) Crashes on and near College Campuses: A Comparative Analysis of Pedestrian and Bicyclist Safety. Journal of the American Planning Association, 80, 198-217. https://doi.org/10.1080/01944363.2014.978354

[42] Li, M., Faghri, A., Ozden, A. and Yue, Y. (2017) Economic Feasibility Study for Pavement Monitoring Using Synthetic Aperture Radar-Based Satellite Remote 
Sensing: Cost-Benefit Analysis. Transportation Research Record: Journal of the Transportation Research Board, No. 2645, 1-11. https://doi.org/10.3141/2645-01

[43] Mohammadiziazi, R., Faghri, A. and Li, M. (2018) The Impacts of Sea Level Rise on Non-Motorized Transportation. Transportation Research Board 97 th Annual Meeting, Washington DC, 7-11 January 2018, Article No. 18-04905.

[44] Kiyota, M., Vandebona, U., Katafuchi, N. and Inoue, S. (2000) Bicycle and Pedestrian Traffic Conflicts on Shared Pavements. 14th Velo-City International Conference Proceedings, Munich.

[45] Suarez, R., Faghri, A. and Li, M. (2014) Evaluation of the Accuracy and Automation of Travel Time and Delay Data Collection Methods. Journal of Transportation Technologies, 4, 72-83. https://doi.org/10.4236/jtts.2014.41007

[46] Berzina, L., Faghri, A., Shourijeh, M. and Li, M. (2013) Evaluation of Travel Time Data Collection Techniques: A Statistical Analysis. International Journal of Traffic and Transportation Engineering, 2, 149-158. https://doi.org/10.5923/j.ijtte.20130206.03

[47] Berzina, L., Faghri, A., Shourijeh, M.T. and Li, M. (2014) Development of a Post-Processing Automation Procedure for the GPS-Based Travel Time Data Collection Technique. Journal of Transportation Technologies, 4, 63-71.

https://doi.org/10.4236/jtts.2014.41006 